
HOSPITAL PRIVADO NO MUNICÍPIO DE SÃO PAULO.

\author{
Luciano Rodrigues de Oliveira; Maria D'Innocenzo \\ Hospital Sírio-Libanês; UNIFESP
}

HOSPITAL SÍRIO-LIBANÊS

\section{INTRODUÇÃO}

- Nas últimas décadas tem sido crescente no mundo inteiro um movimento que busca respostas para os fenômenos de altos custos sociais com a atenção hospitalar e a insatisfatória resposta comprovada pelos indicadores de qualidade de saúde das populações.

- Uma forma de interferir nas reinternações, na alta permanência de pacientes e no programa de seguridade diminuindo custos é por meio do planejamento da alta do hospital para que haja transferência de cuidados da alta complexidade para o ambiente domiciliar de forma segura. $O$ planejamento da alta é benéfico para 0 paciente e interfere significativamente, diminuindo a porcentagem de reinternações.

\section{METODOLOGIA}

\section{Tipo de Estudo}

- Pesquisa descritiva de natureza exploratória, de caráter retrospectivo, com abordagem quantitativa. Entende-se esta abordagem contempla os aspectos do objeto investigado.

- O estudo descritivo objetiva observar, registrar, analisar e correlacionar fatos ou fenômenos (variáveis) sem manipulá-los. Procura descobrir, com a precisão possível, a frequência com que um fenômeno ocorre, sua relação e conexão com outros, sua natureza e características e se necessário podem ser correlacionadas.

\section{OBJETIVO}

\section{Objetivo Geral}

- Descrever o modelo do serviço de desospitalização e avaliar os indicadores deste serviço de desospitalização de um hospital privado no município de São Paulo.

\section{Objetivos Específicos}

- Avaliar a satisfação dos pacientes desospitalizados com relação ao serviço recebido das empresas prestadores de serviços de cuidados continuados.

- Avaliar se o serviço de desospitalização gera impactos na gestão de leitos do hospital.

\section{RESULTADOS}

- Analisados os dados coletados pelo serviço de desospitalização de um Hospital Privado de São Paulo referente a 2035 solicitações de desospitalização de janeiro de 2014 a dezembro de 2016, 72\% delas foram autorizadas pelas fontes pagadoras. Houve queda do de tempo de permanência e tempo médio em dias entre o dia do pedido e o dia da saída real de alta de 5,85 para 4,32 dias. Queda na proporção de pacientes crônicos de 48,5\% para 37,9\%. Avaliado também a satisfação do pacientes e seus familiares com relação ao serviço recebido pelas empresas de home care após a alta hospitalar, sendo em média $74,01 \%$ satisfeitos com a assistência recebida.
Quadro 01 - Situação das solicitações de desospitalização 2014-2016.

\begin{tabular}{|c|c|c|c|c|c|c|c|c|c|c|c|c|c|}
\hline Desospitalização - 2014 & Jan & Fev & Mar & Abr & Mai & Jun & Jul & Ago & Set & Out & Nov & Dez & Total \\
\hline Solicitado & 42 & 53 & 36 & 56 & 65 & 43 & 75 & 62 & 62 & 54 & 46 & 41 & 635 \\
\hline Aprovado & 29 & 39 & 23 & 34 & 40 & 24 & 43 & 46 & 39 & 35 & 33 & 27 & 412 \\
\hline Negado & 13 & 14 & 13 & 22 & 25 & 19 & 32 & 16 & 23 & 19 & 13 & 14 & 223 \\
\hline Desospitalização - 2015 & Jan & Fev & Mar & Abr & Mai & Jun & Jul & Ago & Set & Out & Nov & Dez & Total \\
\hline Solicitado & 35 & 45 & 54 & 49 & 48 & 65 & 54 & 58 & 66 & 59 & 67 & 69 & 669 \\
\hline Autorizado & 27 & 28 & 37 & 36 & 40 & 53 & 41 & 45 & 54 & 41 & 50 & 50 & 502 \\
\hline Negado & 8 & 17 & 17 & 13 & 8 & 12 & 13 & 13 & 12 & 18 & 17 & 19 & 167 \\
\hline Desospitalização - 2016 & Jan & Fev & Mar & Abr & Mai & Jun & Jul & Ago & Set & Out & Nov & Dez & Total \\
\hline Solicitado & 53 & 34 & 55 & 51 & 76 & 70 & 81 & 63 & 67 & 59 & 51 & 71 & 731 \\
\hline Aprovado & 42 & 28 & 46 & 30 & 54 & 50 & 60 & 45 & 49 & 46 & 43 & 58 & 551 \\
\hline Neghte: & lizậ̃o & fulth & 2027 & 21 & 22 & 20 & 21 & 18 & 18 & 13 & 8 & 13 & 180 \\
\hline
\end{tabular}

Quadro 02 - Relação média de permanência hospitalar, média de dias da solicitação e alta e número de pacientes crônicos desospitalizados 2014-2016
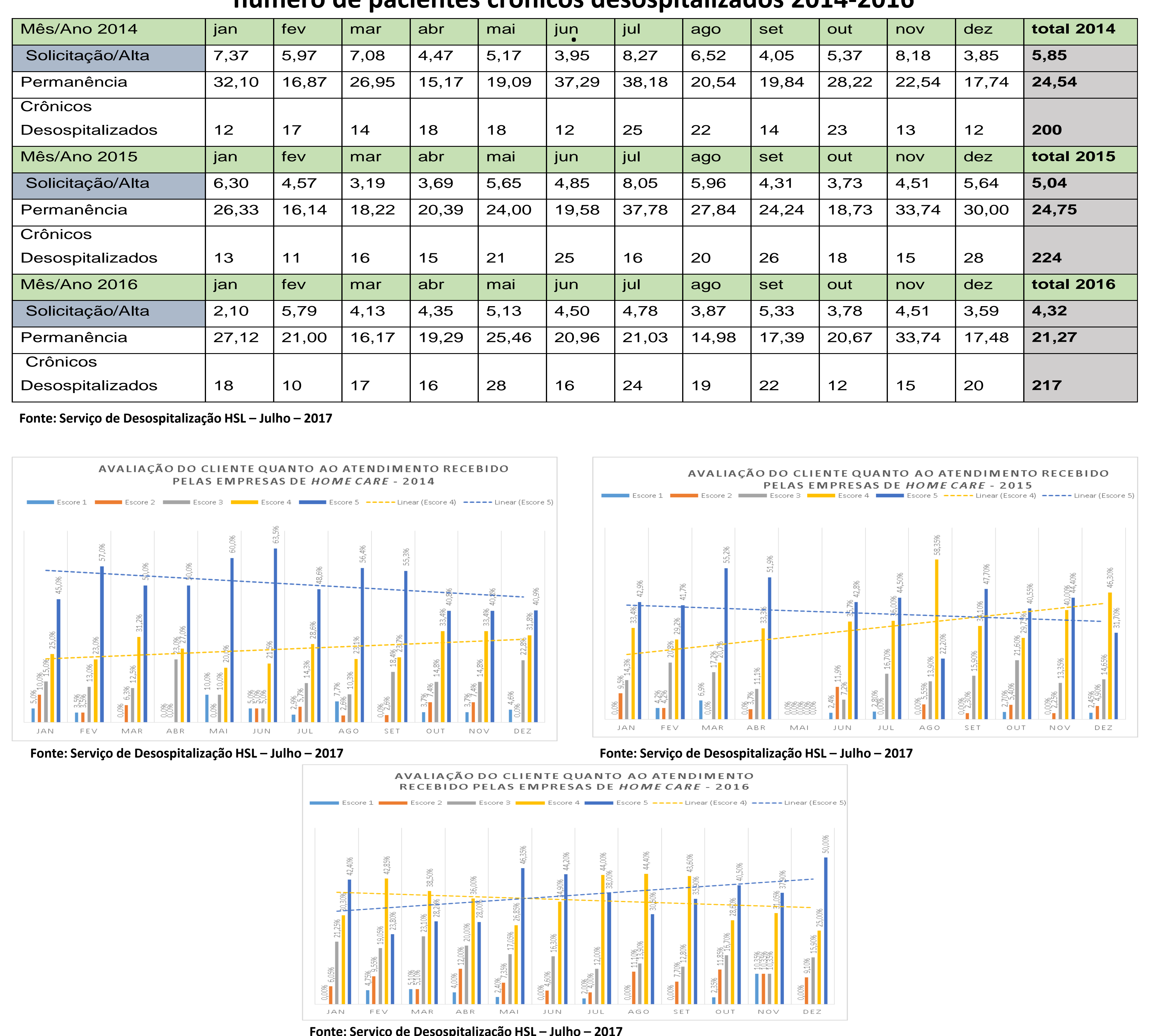

\section{CONCLUSÕES}

Constata-se a inexpressiva produção de conhecimento a respeito de atuações de equipes de desospitalização em instituições hospitalares. Podemos afirmar que a instituição que possui uma equipe ativa e dedicada na gestão da permanência do paciente, gera capacidade para atendimento de pacientes agudos, com aumento do giro e disponibilidade de leitos. Os indicadores mostraram que a atuação de um serviço de desospitalização corroborou com a redução do tempo de permanência hospitalar, do número de pacientes crônicos e, na redução do tempo da efetiva desospitalização. Conclui-se que de maneira geral as famílias e seus pacientes estão satisfeitos com o serviço recebido pelas empresas de assistência domiciliar e demais serviços de cuidados continuados. Admitese a limitação deste estudo, sendo importante a realização de outras investigações para explorar a desospitalização.

\title{
PRINCIPAIS REFERÊNCIAS
}

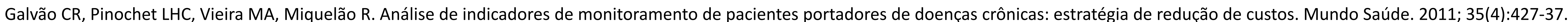

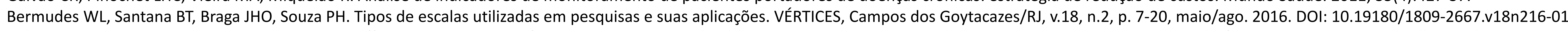

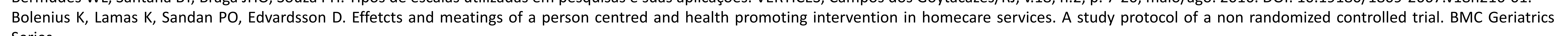
Series. 